\title{
Molecule-dependent oxygen isotopic ratios in the coma of comet 67P/Churyumov-Gerasimenko
}

\author{
K. Altwegg ${ }^{\circledR},{ }^{1 \star}$ H. Balsiger, ${ }^{1}$ M. Combi, ${ }^{2}$ J. De Keyser ${ }^{\circledR},{ }^{3}$ M. N. Drozdovskaya ${ }^{\circledR},{ }^{4}$ S. A. Fuselier, ${ }^{5,6}$ \\ T. I. Gombosi, ${ }^{2}$ N. Hänni ${ }^{\circledR},{ }_{1}^{1}$ M. Rubin ${ }^{\circledR}, 1$ M. Schuhmann, ${ }^{1}$ I. Schroeder ${ }^{\circledR 1}$ and S. Wampfler ${ }^{\circledR 4}$ \\ ${ }^{1}$ Physikalisches Institut, University of Bern, Sidlerstr 5, CH-3012 Bern, Switzerland \\ ${ }^{2}$ Department of Climate and Space Sciences and Engineering, University of Michigan, 2455 Hayward, Ann Arbor, MI 48109, USA \\ ${ }^{3}$ Royal Belgian Institute for Space Aeronomy, BIRA-IASB, Ringlaan 3, B-1180 Brussels, Belgium \\ ${ }^{4}$ Center for Space and Habitability, University of Bern, Gesellschaftsstr 6, CH-3012 Bern, Switzerland \\ ${ }^{5}$ Space Science Directorate, Southwest Research Institute, 6220 Culebra Rd., San Antonio, TX 78228, USA \\ ${ }^{6}$ Department of Physics and Astronomy, The University of Texas at San Antonio, San Antonio, TX 78249, USA
}

Accepted 2020 August 24. Received 2020 August 22; in original form 2020 June 12

\begin{abstract}
The ratios of the three stable oxygen isotopes ${ }^{16} \mathrm{O},{ }^{17} \mathrm{O}$, and ${ }^{18} \mathrm{O}$ on the Earth and, as far as we know in the Solar system, show variations on the order of a few per cent at most, with a few outliers in meteorites. However, in the interstellar medium there are some highly fractionated oxygen isotopic ratios in some specific molecules. The goal of this work is to investigate the oxygen isotopic ratios in different volatile molecules found in the coma of comet 67P/Churyumov-Gerasimenko and compare them with findings from interstellar clouds in order to assess commonalities and differences. To accomplish this goal, we analysed data from the ROSINA instrument on Rosetta during its mission around the comet. ${ }^{16} \mathrm{O} /{ }^{18} \mathrm{O}$ ratios could be determined for $\mathrm{O}_{2}$, methanol, formaldehyde, carbonyl sulfide, and sulfur monoxide/dioxide. For $\mathrm{O}_{2}$ the ${ }^{16} \mathrm{O} /{ }^{17} \mathrm{O}$ ratio is also available. Some ratios are strongly enriched in the heavy isotopes, especially for sulfur-bearing molecules and formaldehyde, whereas for methanol the ratios are compatible with the ones in the Solar system. $\mathrm{O}_{2}$ falls in-between, but its oxygen isotopic ratios clearly differ from water, which likely rules out an origin of $\mathrm{O}_{2}$ from water, be it by radiolysis, dismutation during sublimation, or the Eley-Rideal process from water ions hitting the nucleus as postulated in the literature.
\end{abstract}

Key words: comets: individual: 67P/Churyumov-Gerasimenko.

\section{INTRODUCTION}

Oxygen has three stable isotopes with mean terrestrial abundance ratios: ${ }^{16} \mathrm{O} /{ }^{17} \mathrm{O}=2700,{ }^{16} \mathrm{O} /{ }^{18} \mathrm{O}=490$ (Clayton 2003). From meteoritic research, it is known that oxygen fractionates relatively moderately by fewpercent in the Solar system with a massdependent relationship between variations in ${ }^{16} \mathrm{O} /{ }^{17} \mathrm{O}$ and ${ }^{16} \mathrm{O} /{ }^{18} \mathrm{O}$ ratios (e.g. Ireland et al. 2020). However, in the interstellar medium, large oxygen isotopic fractionations have been found in specific molecules (e.g. Loison et al. 2019). Isotopic ratios in different molecules can help to decipher their formation pathways including the physical boundary conditions. Many chemical reactions have different reaction rates for different isotopes, especially at very cold temperatures. This leads to fractionation with time. In comets, it was recognized already a long time ago, that, for example, the $\mathrm{D} / \mathrm{H}$ ratio in water differs for most comets significantly from the terrestrial value. For heavier atoms, measurements of isotopic ratios in comets are scarce and normally come with big uncertainties. In the interstellar medium, such isotopic fractionation is even more pronounced, not only for hydrogen, but also for heavier atoms. The problem there is the difficulty to measure the main isotopologues as the star-forming regions are very often optically thick for the more abundant species.

Because of the Rosetta mission and the ROSINA instrument (Balsiger et al. 2007), several isotopologues could be measured in the cometary coma of $67 \mathrm{P} /$ Churyumov-Gerasimenko with a relatively high precision. Apart from the deuterated species of $\mathrm{H}_{2} \mathrm{O}$ and $\mathrm{H}_{2} \mathrm{~S}$ (Altwegg et al. 2015; 2017) this is especially true for the isotopologues of $\mathrm{CO}_{2}$ (Hässig et al. 2017), of some sulfur-bearing species (Calmonte et al. 2017), of silicon (Rubin et al. 2017), of some of the halogens (Dhooghe et al. 2017), and of oxygen in water (Schroeder et al. 2019). In addition most stable isotopes of the noble gases Xe (Marty et al. 2017), Kr, and Ar (Rubin et al. 2018) have been detected in the cometary coma. Except for the isotopologues of $\mathrm{CO}_{2}$ and probably the $\mathrm{Ar}$ isotopes, all isotopic ratios measured so far deviate to some degree from the terrestrial or solar values. This deviation clearly points to a pre-solar origin of most molecules detected in $67 \mathrm{P}$ and, in the case of $\mathrm{Si}$ and $\mathrm{Xe}$, where chemistry cannot be the reason for fractionation, also to a non-homogenized solar nebula.

In this paper, we investigate some more oxygenated molecules in order to find out how the composition of $67 \mathrm{P}$ reflects the chemistry during pre-solar stages. Oxygen isotopic ratios can be derived for molecules that are not very rare in the coma of the comet and that have no strong mass interferences with 
neighbouring molecules/fragments. Bulk abundances for such molecules can be found in Rubin et al. (2019). Relative abundances vary with heliocentric distance and latitude. Apart from the abundant water and carbon dioxide, $\mathrm{O}_{2}$ with an abundance of $(3.1 \pm 1.1$ per cent $)$ relative to water, methanol $(0.21 \pm 0.06$ per cent $)$, formaldehyde $\left(0.3 \pm 0.1\right.$ per cent), OCS $\left(0.041_{-0.02}^{+0.08}\right.$ per cent $), S O$ $\left(0.071_{-0.037}^{+0.142}\right.$ percent $)$, and $\mathrm{SO}_{2}\left(0.127_{-0.064}^{+0.254}\right.$ per cent $)$ are accessible for such isotopic studies.

One of the questions to answer is the formation pathway of $\mathrm{O}_{2}$, which has a surprisingly high abundance (Bieler et al. 2015) and for which there exist several hypotheses on its formation. Loison et al. (2019) published a chemical model for the oxygen isotopic fractionation in the gas phase in cold clouds. This model yields high enrichments for the heavy oxygen isotopes in sulfurbearing molecules and $\mathrm{O}_{2}$, but not in methanol and a depletion in formaldehyde. The question remains if this is also reflected in cometary ice.

\section{DATA}

The ROSINA-DFMS mass spectrometer (Balsiger et al. 2007) flown on the Rosetta mission has a mass resolution $\mathrm{m} / \Delta \mathrm{m}$ of $\sim 3000$ at the 1 percent level at $\mathrm{m} / \mathrm{z} 28$, which corresponds to roughly 9000 at full width at half-maximum. The dynamic range of one single spectrum for one integer $\mathrm{m} / \mathrm{z}$ number with an integration time of $20 \mathrm{~s}$ is $\sim 10^{4}$. Depending on the species, this mass resolution and dynamic range limit the detection of the rare isotopologues. This is especially true for ${ }^{17} \mathrm{O}$ in carbon and sulfur-bearing molecules due to interferences with the ${ }^{13} \mathrm{C}$ and ${ }^{33} \mathrm{~S}$ isotopologues. However, the ${ }^{16} \mathrm{O} /{ }^{18} \mathrm{O}$ ratios in $\mathrm{CO}_{2}, \mathrm{H}_{2} \mathrm{O}, \mathrm{O}_{2}, \mathrm{H}_{2} \mathrm{CO}, \mathrm{CH}_{3} \mathrm{OH}, \mathrm{OCS}, \mathrm{SO} / \mathrm{SO}_{2}$ are deduced by choosing special periods, where interference from neighbouring species are minimal and abundances are maximal. In addition, it is possible to deduce also ${ }^{16} \mathrm{O} /{ }^{17} \mathrm{O}$ in the abundant $\mathrm{H}_{2} \mathrm{O}$ and $\mathrm{O}_{2}$. In the following, we discuss the procedures and time range used for the different species. It has to be noted that due to electron impact ionization in the instrument, $\mathrm{SO}$ is a fragment of $\mathrm{SO}_{2}$ and at the same time a parent. The same is true for $\mathrm{CO}$ and $\mathrm{CO}_{2}$. Oxygen isotopic ratios for the monoxides are therefore not independent from the dioxides. All errors listed here or cited from earlier work represent $1 \sigma$ uncertainties.

DFMS peaks are fitted well by two Gaussians where the width of the second Gaussian is approximately three times the width and a 10th of the amplitude of the first (De Keyser et al. 2019). For a single spectrum, these widths are the same for all peaks, but they vary with mass and, due to temperatures effects, also slightly with time. If there is a large peak, these widths are fitted and the fit is applied to smaller peaks or overlapping peaks on the same mass. With this technique, it is possible to fit peaks even if they are mostly hidden inside larger peaks (Fig. 1). For spectra, where the amplitude is low, we omit the second Gaussian, as it is mainly hidden in the background.

The abundance measured by the mass spectrometer depends on the cometocentric distance, on the heliocentric distance and, due to the heterogeneous coma, also on the position of the spacecraft relative to the comet (Northern/Southern hemisphere). Early in the mission, between 2014 end September and end December, the spacecraft was generally inside of $20 \mathrm{~km}$ from the comet. After this time, distances increased, partly due to special trajectories adapted to the needs of other instruments, partly due to the increased activity of the comet. In 2016 March, the spacecraft again reached distances inside of $20 \mathrm{~km}$, but only for a short period before going on to an extended tail excursion. In 2016 May, the spacecraft was inside of $10 \mathrm{~km}$ of the nucleus. At that time, ROSINA successfully targeted
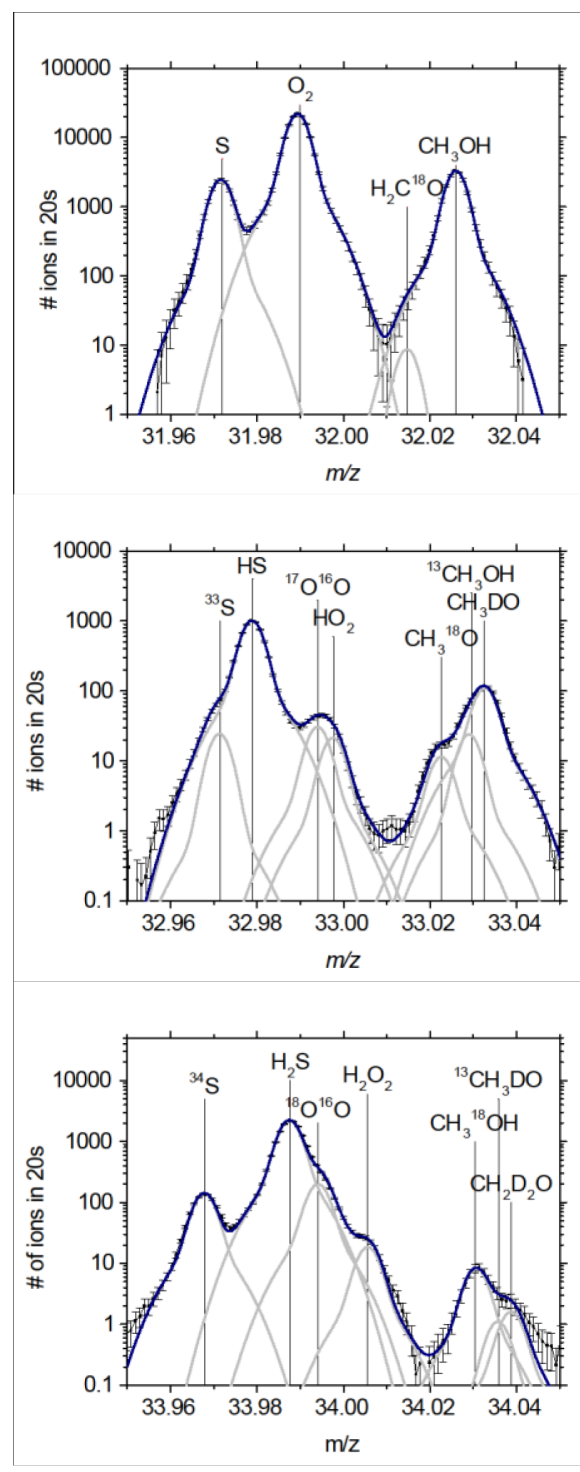

Figure 1. Sample spectra used for the $\mathrm{O}_{2}$ and $\mathrm{CH} 3 \mathrm{OH}$ isotopologues. Average of seven spectra taken on 2014 October 9, October 17, and October 19. The grey lines correspond to the individual fits with the blue line being the sum of all fits.

noble gases and by mid-August, when Rosetta was again close to the nucleus, the activity of the comet had decreased considerably, making the abundance of many of the molecules too low to detect rare isotopologues. This leaves the periods 2014 October-December and the short period in 2016 March as prime periods for this work.

\section{$2.1 \mathrm{CO} / \mathrm{CO}_{2}$}

For $\mathrm{CO}$, there is a strong overlap of $\mathrm{C}^{18} \mathrm{O}$ and $\mathrm{NO}$ and, as a result, a reliable value for ${ }^{16} \mathrm{O} /{ }^{18} \mathrm{O}$ cannot be determined (Rubin et al. 2017). The same authors derived a value of $86.0 \pm 8.5$ for ${ }^{12} \mathrm{C} /{ }^{13} \mathrm{C}$. CO is a parent molecule but also a fragment of $\mathrm{CO}_{2}$ from electron impact ionization and the isotopologues of $\mathrm{CO}$ and $\mathrm{CO}_{2}$ are therefore not independent. Hässig et al. (2017) studied the $\mathrm{CO}_{2}$ isotopologues in detail for two periods early in the mission: 2014 October and 2014 December. There are several interferences, especially the interference between ${ }^{17} \mathrm{O}$ and ${ }^{13} \mathrm{C}$ isotopologues - true for all C-bearing molecules 
- that makes the detection of $\mathrm{C}^{16} \mathrm{O}^{17} \mathrm{O}$ impossible. The $\mathrm{C}^{16} \mathrm{O}^{18} \mathrm{O}$ peak might be contaminated by some $\mathrm{NO}_{2}$, but this is probably not significant. This is discussed in detail by Hässig et al. (2017). Their main argument is a very good correlation between the main isotopologue of $\mathrm{CO}_{2}$ on $\mathrm{m} / \mathrm{z} 44$ with the peak on $\mathrm{m} / \mathrm{z}, 46$, independent of latitude or time period in the mission, which would not be expected if $\mathrm{NO}_{2}$ would significantly interfere. The peak on $\mathrm{m} / \mathrm{z}, 46$ is well resolved and a precise ${ }^{16} \mathrm{O} /{ }^{18} \mathrm{O}$ ratio of $494 \pm 8$ was deduced (Hässig et al. 2017). They also derived a value of $84 \pm 4$ for the ${ }^{12} \mathrm{C} /{ }^{13} \mathrm{C}$ ratio for $\mathrm{CO}_{2}$, in agreement with the value derived for $\mathrm{CO}$ (Rubin et al. 2017).

\section{$2.2 \mathrm{H}_{2} \mathrm{O}$}

For water, the ${ }^{18} \mathrm{O}$ isotopologue is well resolved on $\mathrm{m} / \mathrm{z}, 20$, whereas $\mathrm{H}_{2}{ }^{17} \mathrm{O}$ on $\mathrm{m} / z$. 19 is part of a broad peak together with HDO. Schroeder et al. (2019) evaluated data for the entire mission duration for $\mathrm{H}_{2}{ }^{18} \mathrm{O}$ using also the fragments ${ }^{16} \mathrm{OH}$ and ${ }^{18} \mathrm{OH}$, which are both well separated from neighbouring molecules. $\mathrm{H}_{2}{ }^{17} \mathrm{O}$ needs manual fitting, and ${ }^{17} \mathrm{OH}$ is hidden by $\mathrm{H}_{2} \mathrm{O}$. The analysis of ${ }^{17} \mathrm{O}$ was restricted to two periods, the first one in 2015 May during the inbound equinox, the second one in 2016 March during the second equinox. The first period was chosen as it represents probably best the bulk composition (see Rubin et al. 2019), the second one was a time period where the spacecraft was close to the nucleus and therefore the signal high enough. The evaluation of ${ }^{16} \mathrm{O} /{ }^{18} \mathrm{O}$ shows, after correction for the detector gain due to ageing, that the ratio is constant over the mission. This is consistent with $\mathrm{D} / \mathrm{H}$ in water, for which a very similar ratio was measured early as well as late in the mission (Altwegg et al. 2017). Although we cannot prove it for other species, it is very likely that the oxygen isotope ratios do not change over the mission in general, as mass-dependent effects (e.g. sublimation rates) are probably very minor.

\subsection{2}

The abundance of $\mathrm{O}_{2}$ follows largely the abundance of water (Bieler et al. 2015). The main isotopologue on $\mathrm{m} / \mathrm{z} 32$ is well separated from the neighbouring $\mathrm{S}$ and $\mathrm{CH}_{3} \mathrm{OH}$. The ${ }^{16} \mathrm{O}^{17} \mathrm{O}$ molecule has an interference with $\mathrm{HS}$ and with $\mathrm{HO}_{2}$, but can be reliably fitted. ${ }^{16} \mathrm{O}^{18} \mathrm{O}$ on $m / z, 34$ is on the slope of the abundant $\mathrm{H}_{2} \mathrm{~S}$ peak. However, $\mathrm{H}_{2} \mathrm{~S}$ and $\mathrm{O}_{2}$ do not follow each other (e.g. Läuter et al. 2020). Especially early in the mission, $\mathrm{O}_{2}$ is by far the highest peak on $\mathrm{m} / \mathrm{z}, 32$. To get a reliable value for ${ }^{16} \mathrm{O}^{18} \mathrm{O}$, we therefore used periods where the abundance of $\mathrm{O}_{2}$ is high enough to detect the ${ }^{16} \mathrm{O}^{17} \mathrm{O}$ and where, at the same time, the abundance of $\mathrm{H}_{2} \mathrm{~S}$ is relatively low. These conditions were fulfilled early in the mission. Table $\mathrm{S} 1$ gives the dates and times of the analysed spectra and Fig. S1 shows the individually derived isotopic ratios. Fig. 1 shows sample spectra for $m / z, 32,33$, and 34 for this time period.

\section{$2.4 \mathrm{CH}_{3} \mathrm{OH}$}

The main peak on $\mathrm{m} / \mathrm{z}, 32$ is well separated from neighbouring peaks. $\mathrm{CH}_{3}{ }^{17} \mathrm{OH}$ is hidden by ${ }^{13} \mathrm{CH}_{3} \mathrm{OH}$. However, $\mathrm{CH}_{3}{ }^{18} \mathrm{OH}$ is well separated from neighbouring peaks on $m / z, 34$ (see Fig. 1), except for an interference with deuterated methanol isotopologues ${ }^{13} \mathrm{CH}_{3} \mathrm{DO}$ and $\mathrm{CH}_{2} \mathrm{D}_{2} \mathrm{O}$, which are clearly less abundant. Deuterated methanol will be the topic of a forthcoming paper. Count rates were never high enough to deduce ${ }^{16} \mathrm{O} /{ }^{18} \mathrm{O}$ from single spectra. Therefore, in this case spectra were co-added before the peaks were fitted, using the same spectra as for $\mathrm{O}_{2}$. The resulting ${ }^{16} \mathrm{O} /{ }^{18} \mathrm{O}$ ratio was deduced from the mean value over $3 \mathrm{~d}$, for which each seven spectra were co-added (2014 October 9, October 17, and October 19). We also derived the ${ }^{12} \mathrm{C} /{ }^{13} \mathrm{C}$ ratio for methanol (Fig. 1). ${ }^{13} \mathrm{CH}_{3} \mathrm{OH}$ has some overlap with deuterated methanol, but is reliably fitted for times when methanol is high and statistics therefore not a problem, which are the same periods as used for $\mathrm{O}_{2}$.

\section{$2.5 \mathrm{H}_{2} \mathrm{CO}$}

Analysis of formaldehyde is more difficult. The main peak on $m / z, 30$ is clearly separated from $\mathrm{C}^{18} \mathrm{O}$ and $\mathrm{NO}$, which strongly overlap, and $\mathrm{CH}_{4} \mathrm{~N}$ and $\mathrm{C}_{2} \mathrm{H}_{6}$. However, formaldehyde is never very abundant. In addition, $\mathrm{H}_{2} \mathrm{CO}$ is also a fragment of methanol. Fragmentation patterns measured for methanol for DFMS show that the ratio of the fragment on mass 30 to the parent methanol ion is $\sim 0.1$ (Schuhmann et al. 2019). $\mathrm{H}_{2} \mathrm{C}^{18} \mathrm{O}$ is in the slope of methanol, which has a similar bulk abundance as formaldehyde and the isotopologue also interferes with the much more abundant $\mathrm{O}_{2}$ (see Fig. 2), mainly because of the limited dynamic range of single spectra. For the ${ }^{16} \mathrm{O} /{ }^{18} \mathrm{O}$ in formaldehyde, we need periods when the $\mathrm{O}_{2}$ abundance was relatively low, the signal for $\mathrm{H}_{2} \mathrm{CO}$ was as high as possible, and the ratio methanol/formaldehyde as low as possible. The only time when this was fulfilled was early 2014 October. At that time, methanol was about 10 times smaller than the peak on $\mathrm{m} / \mathrm{z}, 30$ associated with $\mathrm{H}_{2} \mathrm{CO}$. That means the contribution of the methanol fragments to the peaks of formaldehyde is on the order of 1 per cent and is therefore negligible. We analysed data from 2014 October 3 and 4 (Fig. 2). Here, the $\mathrm{H}_{2} \mathrm{C}^{18} \mathrm{O}$ peak is visible.

We also tried to derive the ${ }^{12} \mathrm{C} /{ }^{13} \mathrm{C}$ ratio for formaldehyde (Fig. 2). Because $\mathrm{H}_{2}{ }^{13} \mathrm{CO}$ is hidden by the peak of $\mathrm{CH}_{3} \mathrm{O}$, a fragment of methanol, we looked for a period when we had a very strong formaldehyde signal, a high ratio of formaldehyde to methanol, independent of $\mathrm{O}_{2}$. A period was found in December 2014, where $\mathrm{H}_{2} \mathrm{CO}$ was high, but so was $\mathrm{O}_{2}$. Because of the high $\mathrm{O}_{2}, \mathrm{H}_{2} \mathrm{C}^{18} \mathrm{O}$ cannot be reliably fitted during this period because of the limited dynamic range (Fig. 1). While fitting $\mathrm{m} / \mathrm{z}, 30$ and 31 for $\mathrm{H}_{2}{ }^{13} \mathrm{CO} / \mathrm{H}_{2}{ }^{12} \mathrm{CO}$ with data from the December period, we also derived as a byproduct the ${ }^{12} \mathrm{C}_{2} \mathrm{H}_{6} /{ }^{13} \mathrm{C}^{12} \mathrm{CH}_{6}$ ratio and from there the ${ }^{12} \mathrm{C} /{ }^{13} \mathrm{C}$ ratio in ethane. In the same spectra, there is also the ${ }^{15} \mathrm{NO}$ isotopologue. Nitrogen isotopes will be the topic of another paper. For ethane, we deduced a ${ }^{12} \mathrm{C} /{ }^{13} \mathrm{C}$ ratio of $105 \pm 10$, slightly higher than the value of ${ }^{12} \mathrm{C} /{ }^{13} \mathrm{C}=85.5 \pm 9.0$ deduced by Rubin et al. (2017) for the fragment $\mathrm{C}_{2} \mathrm{H}_{5}$. The difference is mainly due to a better understanding of the ageing of the detector (De Keyser et al. 2019).

\subsection{OCS}

For all sulfur-bearing species, there is a strong interference between the sulfur isotopologues and the oxygen isotopologues. However, the mass differences are such that, at least for ${ }^{18} \mathrm{O}$ and ${ }^{34} \mathrm{~S}$, two separate peaks are fitted for the DFMS mass spectra. The abundance of OCS was highest in 2016 March. The main peak is well separated from oxygenated hydrocarbons. For the ${ }^{18} \mathrm{O}$ isotopologue, there is a weak interference from $\mathrm{CH}_{2} \mathrm{OS}$ (see Fig. 3). A total of 10 spectra from 2016 March 16/17 were co-added before fitting the peaks and deriving the ${ }^{16} \mathrm{O} /{ }^{18} \mathrm{O}$ and the ${ }^{32} \mathrm{~S} /{ }^{34} \mathrm{~S}$ ratios.

\section{7 $\mathrm{SO} / \mathrm{SO}_{2}$}

$\mathrm{SO}$ is a fragment of $\mathrm{SO}_{2}$ from electron impact ionization in the instrument and at the same time also a parent molecule (Calmonte et al. 2016). The isotopologues of the two species are therefore not 

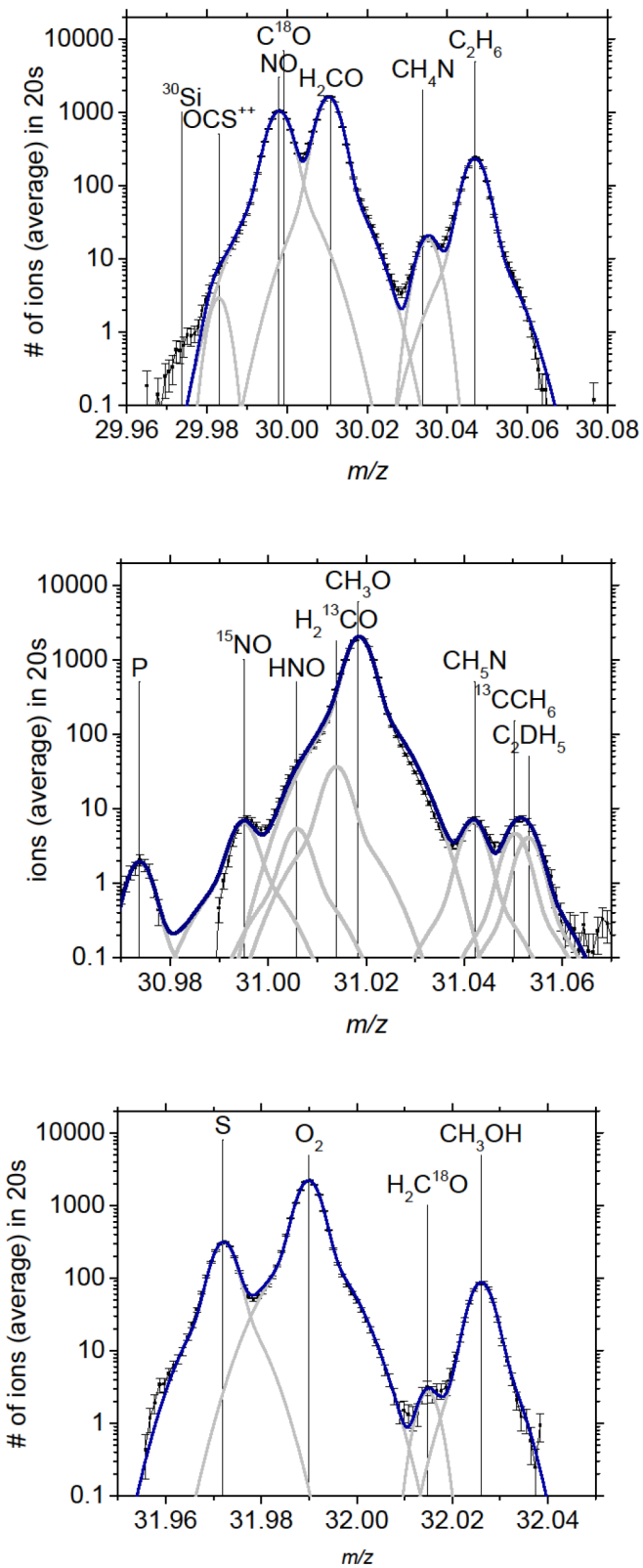

Figure 2. Sample spectra used for the $\mathrm{H}_{2} \mathrm{CO}$ isotopologues. Average of 12 spectra taken on 2014 October 3 and 4 for $\mathrm{m} / z, 30$ and 32. For $\mathrm{m} / \mathrm{z} 31$, the spectrum shown is the average of 10 spectra taken on December 10 (see text for an explanation of chosen periods; the grey lines correspond to the individual fits with the blue line being the sum of all fits).

independent. While SO is well separated from any interfering peak, $\mathrm{SO}_{2}$ interferes with $\mathrm{S}_{2}$, on $\mathrm{m} / \mathrm{z}, 64$ as well as on $\mathrm{m} / \mathrm{z} 66$ (Fig. 4). However, early in the mission $\mathrm{SO}_{2}$ was clearly dominant (Calmonte et al. 2016). Again, the sulfur and oxygen isotopologues are close together in mass. For $\mathrm{SO}_{2}$, the signal for the oxygen isotopologue on $\mathrm{m} / \mathrm{z} 66$ compared to the sulfur isotopologue is twice as high as for $\mathrm{SO}$ due to the two oxygen atoms, but the instrument sensitivity for the $m / z$, range 60-66 is only about 64 per cent compared to $m / z 48$. The highest abundances were measured on 2014 December 09/10. A total of 12 spectra on each day were co-added before fitting the peaks. The two values were then averaged to get the ${ }^{16} \mathrm{O} /{ }^{18} \mathrm{O}$ ratio for $\mathrm{SO}$ and $\mathrm{SO}_{2}$ as well as the ${ }^{32} \mathrm{~S} /{ }^{34} \mathrm{~S}$ ratio.
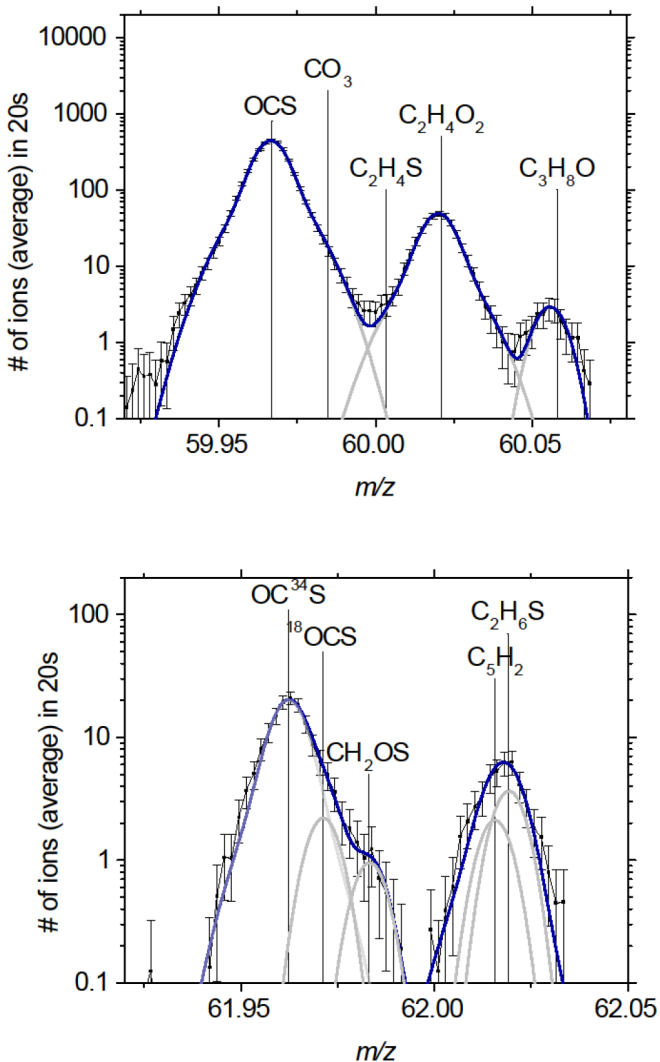

Figure 3. Sample spectra for OCS, average of 10 individual spectra taken on 2016 March 16. The grey lines correspond to the individual fits with the blue line being the sum of all fits.

\subsection{Uncertainties}

While abundances of the main isotopologues are generally well determined with little statistical error, this is not the case for the minor isotopologues. The only species where the uncertainty is low (1.6 percent) is $\mathrm{CO}_{2}$ (Hässig et al. 2017). For $\mathrm{H}_{2} \mathrm{O}$, the error is governed by the uncertainty in the detector gain (see Schroeder et al. 2019). This gain is automatically set by DFMS according to the signal strength and is therefore for the main isotopologue on $\mathrm{m} / \mathrm{z}, 18$ generally significantly different from the gain for the minor ones. This leads to a $1 \sigma$ uncertainty of $\sim 8$ per cent for the ${ }^{16} \mathrm{O} /{ }^{18} \mathrm{O}$ ratio. For the other species, the gain is mostly on the highest level for all isotopologues, which means its uncertainty cancels out. The main uncertainty therefore is due to statistics and fitting errors. This is especially true for $\mathrm{H}_{2} \mathrm{CO}$, where the number of usable spectra is very limited. For the other species, the uncertainty of the ${ }^{16} \mathrm{O} /{ }^{18} \mathrm{O}$ ratio is $10-30$ per cent.

\section{RESULTS}

The ROSINA data to date allowed the derivation of the ${ }^{16} \mathrm{O} /{ }^{18} \mathrm{O}$ ratio for eight different volatile molecules in the coma of 67P. For two of them, the ratio ${ }^{16} \mathrm{O} /{ }^{17} \mathrm{O}$ is available. For the sulfur-bearing molecules the sulfur isotope ratio ${ }^{32} \mathrm{~S} /{ }^{34} \mathrm{~S}$ was derived from the exact same data set, as there is an interference between sulfur and oxygen isotopes. This allows a direct comparison of these ratios, which show strong deviations from terrestrial in oxygen but not sulfur. We were able to also derive some carbon isotopic ratios at the same time. All results with their uncertainties are given in Table 1 and the ${ }^{16} \mathrm{O} /{ }^{18} \mathrm{O}$ ratios also in Fig. 5. 

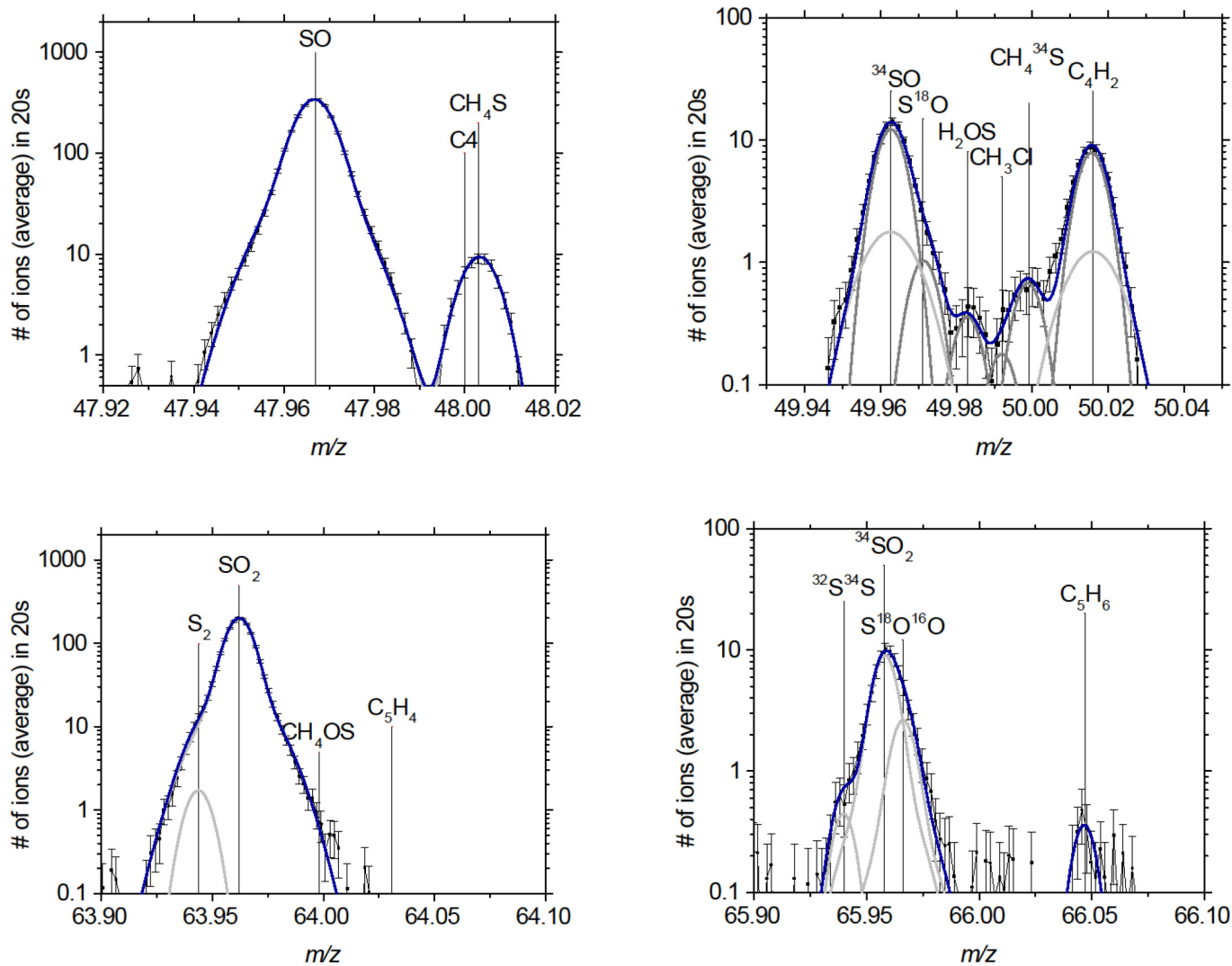

Figure 4. Sample spectra for $\mathrm{SO}$ and $\mathrm{SO}_{2}$. Shown are averaged spectra from 12 individual spectra on 2014 December 10 . The grey lines correspond to the individual fits with the blue line being the sum of all fits.

Table 1. Oxygen, carbon, and sulfur isotopic ratios with $1 \sigma$ errors.

\begin{tabular}{lccccc}
\hline Species & $\begin{array}{c}{ }^{16} \mathrm{O} /{ }^{18} \mathrm{O} \\
(\text { terrestrial } \\
\left.498.7^{\mathrm{a}} / \text { solar } 530^{\mathrm{b}}\right)\end{array}$ & $\begin{array}{c}{ }^{16} \mathrm{O} /{ }^{17} \mathrm{O} \\
(\text { terrestrial } \\
\left.2632^{\mathrm{a}} / \text { solar } 2798^{\mathrm{b}}\right)\end{array}$ & $\begin{array}{c}{ }^{32} \mathrm{~S} /{ }^{34} \mathrm{~S} \\
(\text { standard Solar } \\
\left.\text { System } 22.64^{\mathrm{c}}\right)\end{array}$ & $\begin{array}{c}{ }^{12} \mathrm{C} /{ }^{13} \mathrm{C} \\
\text { (terrestrial } 92.4^{\mathrm{d}} \\
\left./ \text { solar } 88.88^{\mathrm{e}}\right)\end{array}$ & Reference \\
\hline $\mathrm{H}_{2} \mathrm{O}$ & $445 \pm 35$ & $2182 \pm 170$ & - & - & - \\
$\mathrm{O}_{2}$ & $345 \pm 40$ & $1544 \pm 308$ & - & - & Schroeder et al. (2019) \\
$\mathrm{CO}_{2}$ & $494 \pm 8$ & - & - & $86 \pm 4$ & $\begin{array}{c}\text { This work } \\
\mathrm{CO}\end{array}$ \\
$\mathrm{CH}_{3} \mathrm{OH}$ & $495 \pm 40$ & - & - & $91 \pm 10$ & Hässig et al. (2017) \\
$\mathrm{H}_{2} \mathrm{CO}$ & $256 \pm 100$ & - & - & $40 \pm 14$ & Rubin et al. (2017) \\
$\mathrm{SO}$ & $239 \pm 52$ & - & $23.5 \pm 2.5$ & - & This work \\
$\mathrm{SO}_{2}$ & $248 \pm 88$ & - & $21.3 \pm 2.1$ & - & This work \\
$\mathrm{OCS}$ & $277 \pm 70$ & - & $21.7 \pm 4.0$ & - & This work \\
$\mathrm{C}_{2} \mathrm{H}_{6}$ & - & - & - & $105 \pm 10$ & This work \\
\hline
\end{tabular}

Notes: ${ }^{\mathrm{a} C l a y t o n}(2003){ }^{\mathrm{b}} \mathrm{Mc}$ Keegan et al. (2011) ${ }^{\mathrm{c}}$ Robinson (1995) ${ }^{\mathrm{d}}$ Boutton (1991) ${ }^{\mathrm{e}}$ Meibom et al. (2007)

From the table and Fig. 5, it is clear that, albeit the error bars, variations between oxygen isotopic fractionation are quite large. On one end, there are ratios in $\mathrm{CO}_{2}$ and methanol, which are compatible with terrestrial values, at the other end there are ratios in all sulfurbearing molecules, formaldehyde and $\mathrm{O}_{2}$, which are enriched in ${ }^{18} \mathrm{O}$ by a factor 2 . Water is somewhere in-between. Sulfur isotopes do not vary very much and are all, within their uncertainties, compatible with the standard value from the Vienna-Canyon Diablo Troilite (VCDT; Robinson 1995). Surprisingly, carbon isotopic fractionation displays some large differences between species.

\section{DISCUSSION}

\section{1 $\mathrm{H}_{2} \mathrm{O}$}

Water is enriched relative to terrestrial values in the heavy isotopologues by $(17 \pm 6)$ percent and $(11 \pm 7)$ percent for ${ }^{17} \mathrm{O}$ and ${ }^{18} \mathrm{O}$, respectively (Schroeder et al. 2019). It has been shown by the same authors that this value is compatible with self-shielding models which predict a 5-20 percent enrichment (Lyons \& Young 2005; Young 2007; Lee, Bergin \& Lyons 2008). Values measured remotely in different comets show a diverse picture. But due to the large 


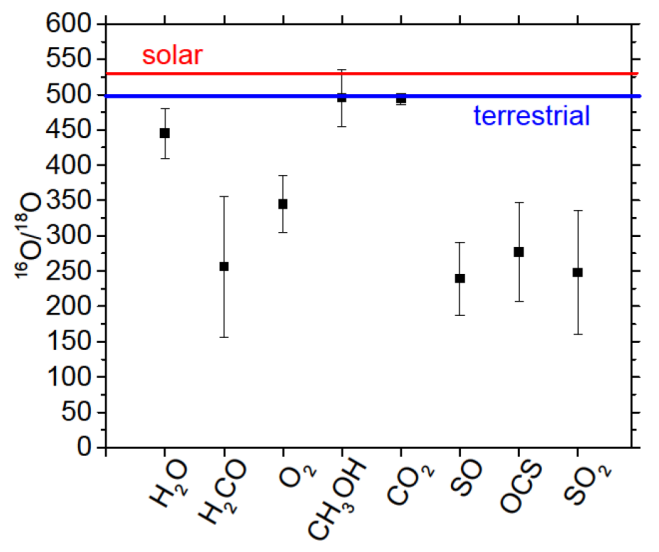

Figure 5. ${ }^{16} \mathrm{O} /{ }^{18} \mathrm{O}$ ratios for eight different molecules ordered by mass. $\mathrm{CO}_{2}$ from Hässig et al. (2017); $\mathrm{H}_{2} \mathrm{O}$ from Schroeder et al. (2019); all other molecules from this work. The red line denotes the solar value; the blue line the terrestrial.

uncertainties, they are mostly compatible with the value derived for 67P as well as with the terrestrial value (see Schroeder et al. 2019 and references therein). It is difficult to conclude that self-shielding is really the cause for this fractionation. Other molecules are much more fractionated than water and probably need another explanation, which then may also be applicable to water.

\section{$4.2 \mathrm{O}_{2}$}

Oxygen is enriched in the heavy isotopes by $(41 \pm 18)$ percent and $(30 \pm 7)$ percent for ${ }^{17} \mathrm{O}$ and ${ }^{18} \mathrm{O}$ relative to terrestrial. The relative enrichment of ${ }^{18} \mathrm{O}$ to ${ }^{17} \mathrm{O}$ is similar to that of water with ${ }^{18} \mathrm{O} /{ }^{17} \mathrm{O}=4.5 \pm 1.0$ for $\mathrm{O}_{2}$ and $4.9 \pm 0.5$ for water, respectively. While error bars are rather large, it is nevertheless clear that the isotopic fractionation in $\mathrm{O}_{2}$ for both heavy oxygen isotopes is not compatible with water. The incompatibility with water immediately rules out the proposed mechanisms based on water for the origin of molecular oxygen in 67P, such as radiolysis from water (Mousis et al. 2016) and dismutation of $\mathrm{H}_{2} \mathrm{O}_{2}$ (Dulieu, Minissale \& BockeléeMorvan 2017). Apart from other arguments (e.g. Heritier et al. 2018), it also rules out the Eley-Rideal scenario proposed by Yao et al. (2017), especially as the oxygen isotopic ratio found in the dust of 67P is close to solar (Paquette et al. 2018). Interaction between energetic water ions and the surface of $67 \mathrm{P}$ is very unlikely to yield highly fractionated $\mathrm{O}_{2}$. This leaves a primordial origin of $\mathrm{O}_{2}$ as described in Taquet et al. (2016) for grain-surface chemistry or gas phase chemistry as described in Rawlings, Wilson \& Williams (2019).

\section{3 $\mathrm{CO}, \mathrm{CO}_{2}, \mathrm{H}_{2} \mathrm{CO}, \mathrm{CH}_{3} \mathrm{OH}$}

$\mathrm{CO}_{2}$ in 67P has a terrestrial value (Hässig et al. 2017) for oxygen isotopes, but it is not compatible with the value derived from solar wind for the Sun. Methanol is compatible with the terrestrial fractionation, but, within error bars, also with the solar value for ${ }^{16} \mathrm{O} /{ }^{18} \mathrm{O}$. Chemically, methanol is probably a product from $\mathrm{CO}$ by successive hydrogenation on cold grains (e.g. Watanabe \& Kouchi 2002). In this case, it would make sense that $\mathrm{CO}_{2}$ and methanol share the same oxygen isotopic fractionation, but only if $\mathrm{CO}_{2}$ is the product of oxygenation of $\mathrm{CO}$ from an isotopically solar/terrestriallike reservoir. Possible scenarios on the interconnection between $\mathrm{CO}$ and $\mathrm{CO}_{2}$ in comets are discussed in A'Hearn et al. (2012). The strong mass interference of $\mathrm{C}^{18} \mathrm{O}$ and $\mathrm{NO}$ and the fact that $\mathrm{CO}$ is not only a parent, but also a fragment of $\mathrm{CO}_{2}$ from electron impact ionization make it impossible to derive a meaningful value for the ${ }^{16} \mathrm{O} /{ }^{18} \mathrm{O}$ in the parent $\mathrm{CO}$ from ROSINA. In order to assess better the situation between $\mathrm{CO}_{2}$ and $\mathrm{CH}_{3} \mathrm{OH}$, we also derived the ${ }^{12} \mathrm{C} /{ }^{13} \mathrm{C}$ ratio (see Fig. 1) for methanol. This ratio is $84 \pm 4$ for $\mathrm{CO}_{2}$ as derived by Hässig et al. (2017) and $86 \pm 8$ for CO (Rubin et al. 2017). For methanol we determine a ratio of $91 \pm 10$, which overlaps within error bars with the ratios for $\mathrm{CO}$ and $\mathrm{CO}_{2}$. This strengthens the formation pathway of methanol and $\mathrm{CO}_{2}$, both starting with $\mathrm{CO}$.

One would expect that $\mathrm{H}_{2} \mathrm{CO}$ and $\mathrm{CH}_{3} \mathrm{OH}$ also share the same isotopic fractionation for $\mathrm{C}$ as well as for $\mathrm{O}$ if most of the $\mathrm{H}_{2} \mathrm{CO}$ is formed by the same mechanism as methanol, namely by successive hydrogenation of $\mathrm{CO}$. However, our result with ${ }^{16} \mathrm{O} /{ }^{18} \mathrm{O}=256 \pm 100$ clearly has a substantial enrichment of ${ }^{18} \mathrm{O}$ for formaldehyde, yet this enrichment is not seen for methanol. For formaldehyde deriving a value for $\mathrm{H}_{2}{ }^{13} \mathrm{CO}$ is challenging, but the evaluation of spectra measured over two days gave very consistent results with $\mathrm{H}_{2}{ }^{12} \mathrm{CO} / \mathrm{H}_{2}{ }^{13} \mathrm{CO}=40 \pm 14$, clearly lower than for $\mathrm{CO}_{2}$ or methanol. This strengthens the notion that $\mathrm{H}_{2} \mathrm{CO}$ and $\mathrm{CH}_{3} \mathrm{OH}$ do not share their formation pathway. The ratio of $6 \pm 2$ for $\mathrm{H}_{2}{ }^{13} \mathrm{CO} / \mathrm{H}_{2} \mathrm{C}^{18} \mathrm{O}$ is compatible with solar and with most measured interstellar values (e.g. Henkel, Wilson \& Downes 1979; Kutner et al. 1982). This ratio therefore cannot be used as argument that oxygen and carbon isotopic ratios are solar.

Measured ${ }^{12} \mathrm{C} /{ }^{13} \mathrm{C}$ ratios in the interstellar medium yield a somewhat heterogeneous picture. In a review article, Wilson \& Rood (1994) claim that the ${ }^{12} \mathrm{C} /{ }^{13} \mathrm{C}$ ratio shows a clear trend with distance to the Galactic Centre. The values are generally higher for $\mathrm{H}_{2} \mathrm{CO}$ than for CO. A recent paper by Persson et al. (2018) has solid numbers for ${ }^{12} \mathrm{C} /{ }^{13} \mathrm{C}$ and ${ }^{18} \mathrm{O} /{ }^{16} \mathrm{O}$ in formaldehyde towards IRAS 16293 $2422 \mathrm{~B}$, a low-mass star-forming region. Unfortunately, there are no values for methanol. It is, however, interesting to note that in this case ${ }^{12} \mathrm{C} /{ }^{13} \mathrm{C}=56$, which is significantly lower than solar while ${ }^{16} \mathrm{O} /{ }^{18} \mathrm{O}$ is around 800 , which is significantly higher than solar for formaldehyde.

Wirström et al. (2011a,b) have measured strong differences in the carbon isotopic fractionation for $\mathrm{CO}$ and $\mathrm{CH}_{3} \mathrm{OH}$ compared to $\mathrm{H}_{2} \mathrm{CO}$ in massive young stellar objects (YSOs). They derived ${ }^{12} \mathrm{C} /{ }^{13} \mathrm{C}$ ratios for $\mathrm{CO}$ and $\mathrm{CH}_{3} \mathrm{OH}$ in different YSOs, demonstrating that in most cases the ratios were equal for the two molecules within error bars, although they differ from source to source. The picture is very different for $\mathrm{H}_{2} \mathrm{CO}$, where the ratio deviates significantly from the one of $\mathrm{CO}$ in the same source. This clearly points to a different formation mechanism for the two molecules. It is argued that, in principle, ${ }^{12} \mathrm{C} /{ }^{13} \mathrm{C}$ is expected to be higher for molecules formed in the gas phase as $\mathrm{CO}$ freezes out on to cold grains with a preference for the heavy isotopes, which then leaves $\mathrm{CO}$ in the gas phase enriched in ${ }^{12} \mathrm{C}$ and also ${ }^{16} \mathrm{O}$. The results by Wirström et al. (2011b), e.g. the source DR21 $(\mathrm{OH})$ with a ${ }^{12} \mathrm{C} /{ }^{13} \mathrm{C}$ ratio of $58 \pm 8$ for $\mathrm{CO}$ and $55 \pm 8$ for methanol as opposed to $\sim 18$ for formaldehyde shows the contrary. Even if these massive YSOs are probably not good proxies for our solar system, our results with different oxygen and carbon isotopic fractionation for methanol and formaldehyde are very much in line with these observations. The heterogeneous picture for formaldehyde and methanol may reflect the fact that part of $\mathrm{H}_{2} \mathrm{CO}$ is formed by hydrogenation along with $\mathrm{CH}_{3} \mathrm{OH}$, but another part may also be a product of gas phase chemistry (van der Tak, van Dishoeck \& Caselli 2000). However, there are unfortunately little data for methanol and formaldehyde for the same sources measured with the same technique/telescope. 


\subsection{Sulfur-bearing oxygenated molecules}

All oxygenated sulfur-bearing molecules share a similar oxygen isotopic fractionation with a depletion of ${ }^{16} \mathrm{O} /{ }^{18} \mathrm{O}$ of almost a factor of 2 relative to terrestrial. Their ratios are very similar to that for $\mathrm{H}_{2} \mathrm{CO}$. On the other hand, the sulfur isotopic ratios are, within error bars, compatible with the VCDT standard for sulfur (Robinson 1995). For the sulfur species $\mathrm{H}_{2} \mathrm{~S}, \mathrm{CS}_{2}$, and OCS in 67P Calmonte et al. (2017) found a slight depletion in the heavy sulfur isotopes. A depletion in the heavy sulfur isotopes cannot be confirmed or ruled out for the oxygenated species considered here, as the error bars are too large. The average ${ }^{34} \mathrm{~S} /{ }^{18} \mathrm{O}$ is $11.4 \pm 3.3$ for the sulfur-bearing oxygenated species. There are values for the OCS minor isotopologues in source B of IRAS 16 293-2422 (Drozdovskaya et al. 2018). For this source ${ }^{34} \mathrm{~S} /{ }^{18} \mathrm{O}$ is 20 and ${ }^{13} \mathrm{C} /{ }^{18} \mathrm{O}=10$. The uncertainties of these ratios are $\sim 30$ per cent. As the main isotopologue is optically thick in source B of IRAS 16 293-2422, there are no meaningful ratios for sulfur or oxygen isotopes in this survey. However, a survey towards Orion KL of carbon-sulfur species by Tercero et al. (2010) gives ${ }^{16} \mathrm{O} /{ }^{18} \mathrm{O}$ ratios for OCS of $200 \pm 112$ and $250 \pm 135$ for the extended ridge and the plateau, respectively. These values are very much in accordance with our measurements, even though Orion KL may again not be a good proxy for our Solar system.

$\mathrm{SO}$ and $\mathrm{SO}_{2}$ measured by ROSINA are not independent as $\mathrm{SO}$ is a fragment of $\mathrm{SO}_{2}$ in the mass spectrometer. Not surprisingly, their oxygen isotopic ratios are very similar with an enrichment of the ${ }^{18} \mathrm{O}$ by a factor 2 relative to solar. For SO, there are data for four different dense clouds/cores by Loison et al. (2019) for the ${ }^{16} \mathrm{O} /{ }^{18} \mathrm{O}$ ratios. They range from 70 to 170 , i.e. even more enriched in heavy isotopes than our values.

Loison et al. (2019) also modelled the oxygen fractionation as a function of time in cold, dense clouds. They found a large ${ }^{18} \mathrm{O}$ enrichment in the gas phase for OCS, $\mathrm{SO}, \mathrm{SO}_{2}$, and $\mathrm{O}_{2}$ after about $10^{5} \mathrm{yr}$, but a depletion for $\mathrm{H}_{2} \mathrm{CO}$, mostly due to isotopic exchange reactions. Water $(\mathrm{OH})$ is slightly enriched in their model, methanol stays almost constant with time. Our results show a very similar trend except for formaldehyde. Even if this model is for the gas phase of cold clouds at $10 \mathrm{~K}$ and therefore not directly applicable for the ice in comets, the mechanisms at play may be very similar. The problem with formaldehyde, as outlined above, is not yet understood.

\section{CONCLUSIONS}

During the Rosetta mission, we found conditions favorable to study oxygen isotopologues for different molecules in the coma of 67P. While the isotopologues of water and $\mathrm{CO}_{2}$ have been published earlier by Schroeder et al. (2019) and by Hässig et al. (2017), respectively, in this paper we deduced ${ }^{16} \mathrm{O} /{ }^{17} \mathrm{O}$ and ${ }^{16} \mathrm{O} /{ }^{18} \mathrm{O}$ for $\mathrm{O}_{2}$, and ${ }^{16} \mathrm{O} /{ }^{18} \mathrm{O}$ for methanol, formaldehyde, carbonyl sulfide, and sulfur monoxide/dioxide. Except for $\mathrm{CO}_{2}$ and methanol, all heavy isotopologues are enriched relative to terrestrial/solar values, but to different degrees. Water is enriched by less than 20 per cent in both heavy isotopologues relative to solar, while all the other species are enriched by roughly a factor 2 . For some of the species, we also looked at the carbon isotopologues and found an enrichment in ${ }^{13} \mathrm{C}$ for formaldehyde, while the values for $\mathrm{CO}$ (Rubin et al. 2017), $\mathrm{CO}_{2}$ (Hässig et al. 2017), and methanol are compatible with terrestrial.

Our values seem to fit well the (relatively scarce) values measured in the ISM, although most of these measurements were done in massive cores, which may not be representative for the origin of the cometary material. The model by Loison et al. (2019) for the enrichment of ${ }^{18} \mathrm{O}$ in the gas phase in a cold cloud may also not be representative, but it is likely that the reactions used in this model, especially the isotopic transfer reactions, were also at play when the material formed that now makes up comet 67P. The riddle about the formation of methanol and formaldehyde has been pointed out before. While it is very likely that methanol formed from $\mathrm{CO}$ on dust grains by hydrogenation as they share their oxygen and carbon isotopic ratios, formaldehyde has probably followed another pathway of formation, seen from the different carbon and oxygen isotopologues in the ISM (Wirström et al. 2011b) as well as in comet 67P.

The isotopic ratios of $\mathrm{O}_{2}$ found in 67P, which do not match the water isotopic ratios, rule out several of the proposed formation scenarios of $\mathrm{O}_{2}$ and, at least for the moment, point to a primordial origin of this quite abundant species.

\section{ACKNOWLEDGEMENTS}

ROSINA would not have produced such outstanding results without the work of the many engineers, technicians, and scientists involved in the mission, in the Rosetta spacecraft team, and in the ROSINA instrument team over the last $20 \mathrm{yr}$, whose contributions are gratefully acknowledged. Rosetta is an ESA mission with contributions from its member states and NASA. We acknowledge herewith the work of the whole ESA Rosetta team. We also would like to thank the anonymous reviewer for the very helpful comments. Work at the University of Bern was funded by the State of Bern, the Swiss National Science Foundation (SNSF; 200020_182418), the Swiss State Secretariat for Education, Research and Innovation (SERI) under contract number 16.0008-2, and by the European Space Agency's PRODEX Program. SFW acknowledges the financial support of the SNSF Eccellenza Professorial Fellowship PCEFP2_181150. JDK acknowledges support by the Belgian Science Policy Office via PRODEX/ROSINA PEA 90020. SAF acknowledges JPL contract 1496541. Work at UoM was supported by contracts JPL 1266313 and JPL 1266314 from the US Rosetta Project. MND is supported by the SNSF Ambizione grant 180079 and the IAU Gruber Foundation Fellowship.

\section{DATA AVAILABILITY}

The data underlying this article are available from the ESA Rosetta data archive at https://www.cosmos.esa.int/web/psa/rosetta and its mirror site at NASA Small Bodies Node https://pds-smallbodies.as tro.umd.edu/data_sb/missions/rosetta/index.shtml

\section{REFERENCES}

A'Hearn M.F. et al., 2012, ApJ, 758, 29

Altwegg K. et al., 2015, Science, 347, 1261952

Altwegg K. et al., 2017, Phil. Trans. R. Soc. , 375, 20160253

Balsiger H. et al., 2007, Space Sci. Rev., 128, 745

Bieler A. et al., 2015, Nature, 526, 678

Boutton T. W., 1991, Carbon Isot. Tech., 1, 155

Calmonte U. et al., 2016, MNRAS, 462, S253

Calmonte U. et al., 2017, MNRAS, 469, S787

Clayton R. N., 2003, in Solar System History from Isotopic Signatures of Volatile Elements. Springer, Dordrecht,p. 19

De Keyser J. et al., 2019, Int. J. Mass Spectrom., 446, 116232

Dhooghe F. et al., 2017, MNRAS, 472, 1336

Drozdovskaya M. N. et al., 2018, MNRAS, 476, 4949

Dulieu F., Minissale M., Bockelée-Morvan D., 2017, Astron. Astrophys., 597, A56

Henkel C., Wilson T. L., Downes D., 1979, Astron. Astrophys. Lett. 73, L13

Heritier K. L., et al., 2018, Nat. Commun., 9, 1 
Hässig M. et al., 2017, A\&A, 605, A50

Ireland T. R. et al., 2020, Space Science Research, 216, 1

Kutner M. L., Machnik D. E., Tucker K. D., Massano W., 1982, ApJ, 254, 538

Lee J.-E., Bergin E. A., Lyons J. R. 2008, Meteor. Planet. Sci., 43, 1351

Loison J. C. et al., 2019, MNRAS, 485, 5777

Lyons J. R., Young E. D. 2005, Nature, 435, 317

Läuter M., Kramer T., Rubin M., Altwegg K., 2020, MNRAS, 498, 3995

Marty B. et al., 2017, Science, 356, 1069

McKeegan K. D. et al., 2011, Science, 332, 1528

Meibom A et al., 2007, ApJ, 656, L33

Mousis O. et al., 2016, ApJ, 823, L41

Paquette J. A. et al., 2018, MNRAS, 477, 3836

Persson M. V. et al., 2018, A\&A, 610, A54

Rawlings J. M. C., Wilson T. G., Williams D. A., 2019, MNRAS, 486, 10

Robinson B. W., 1995, Int. At. Energy Agency TECDOC, 825, 39

Rubin M. et al., 2017, A\&A, 601, A123

Rubin M. et al., 2018, Science Adv., 4, eaar6297

Rubin M. et al., 2019, MNRAS, 489, 594

Schroeder I. R. et al., 2019, A\&A, 630, A29

Schuhmann M. et al., 2019, ACS Earth Space Chem., 3, 1854

Taquet V., Furuya K., Walsh C., van Dishoeck E. F., 2016, MNRAS, 462, S99

Tercero B., Cernicharo J., Pardo J. R., Goicoechea J. R., 2010, A\&A, 517, A96

van der Tak F. F., van Dishoeck E. F., Caselli P., 2000, A\&A, 361, 327
Watanabe N., Kouchi A., 2002, ApJ, 571, L173

Wilson T. L., Rood R. T., 1994, Annu. Rev. Astron. Astrophys., 32, 191

Wirström E. S. et al., 2011a, A\&A, 533, A24

Wirström E. S., Geppert W. D., Persson C. M., Charnley S. B., 2011b, Proc.

IAU Symp. 280, The Molecular Universe. Kluwer, Spain, p. 384

Yao Y., Giapis K. P., 2017, Nat. Commun., 8, 1

Young E. D., 2007, Earth Planet. Sci. Lett., 262, 468

\section{SUPPORTING INFORMATION}

Supplementary data are available at MNRAS online.

Table S1: date and times of analysed $\mathrm{O}_{2}$ isotopologues.

Figure S1: Individual results for the oxygen isotopic ratios in $\mathrm{O}_{2}$.

Please note: Oxford University Press is not responsible for the content or functionality of any supporting materials supplied by the authors. Any queries (other than missing material) should be directed to the corresponding author for the article.

This paper has been typeset from a Microsoft Word file prepared by the author. 